\title{
Research Article \\ Association of serum magnesium levels with glycosylated hemoglobin and degree of neuropathy in patients with diabetic peripheral neuropathy
}

\author{
Sumit Jhajharia', Jyotirmayee Bahinipati ${ }^{1}$, Tapaswini Pradhan ${ }^{2}$ \\ ${ }^{1}$ Associate Professor, ${ }^{2}$ Professor, Department of Biochemistry, Kalinga Institute of Medical Sciences, Bhubaneswar, \\ 751 024, Odisha, India
}

(Received: May $2020 \quad$ Revised: October $2020 \quad$ Accepted: October 2020)

Corresponding author: Jyotirmayee Bahinipati. Email: jyotirmayee.bahinipati@kims.ac.in

\begin{abstract}
Introduction and Aim: Magnesium plays an important role in carbohydrate metabolism and insulin response. Deficiency of magnesium can increase the incidence of Type 2 DM and complications associated with it. Diabetic peripheral neuropathy (DPN) has become the most common chronic diabetic complication affecting about half of the diabetic patients. DPN causes debilitating complications like foot ulcers, gangrene leading to lower limb amputation reducing the quality of life in Diabetic patients. The aim of this study was to find out the levels of serum magnesium in DPN and find its association with severity of neuropathy in DPN.
\end{abstract}

Materials and Methods: Total 286 participants with signs and symptoms of DPN were recruited for the study. They were classified into different severity according to their VPT scoring. Fasting and Postprandial venous blood sample were collected for estimation of $\mathrm{FBS}, \mathrm{HbA}_{1} \mathrm{C}$, serum Magnesium and PPBS respectively. Serum magnesium was found in different severities of neuropathy in DPN. Correlation between serum magnesium, $\mathrm{Hb}_{1} \mathrm{C}$ and severity of DPN was done.

Results: Mean serum magnesium was $1.62 \pm 0.38 \mathrm{mg} / \mathrm{dL}$. There was statistically significant decrease in serum magnesium with an increase in severity of DPN. Significant correlation was seen between serum magnesium and FBS, PPBS, $\mathrm{HbA}_{1} \mathrm{C}$ and VPT scoring in DPN patients.

Conclusion: Hypomagnesemia was found to be associated with DPN and its severity suggesting low serum magnesium may affect peripheral nerve function. Hence, regular monitoring of serum magnesium should be done to prevent chronic complications related to Type2 DM.

Keywords: Diabetic peripheral neuropathy; VPT; FBS; PPBS; serum magnesium; $\mathrm{HbA}_{1} \mathrm{C}$

\section{INTRODUCTION}

$\mathrm{D}$ iabetes has reached the stature of epidemic proportions. International Diabetic Federation estimated a prevalence of diabetes mellitus of 425 million worldwide in 2017 and suggested it will rise to 628 million by 2045 (1). According to the ICMR-INDIAB study, there are 62.4 million people with diabetes in India (2). With the rise in the prevalence of diabetes mellitus, there is an accompanying increase in the prevalence of complications of diabetes. The complication of diabetes mellitus develops when tissues are chronically exposed to high blood glucose levels. The non-enzymatic glycosylation of protein and the accumulation of sorbitol can cause irreversible changes in tissues. Despite improvements in the management of diabetes, diabetic peripheral neuropathy has become the most commonly reported chronic diabetic complication, affecting about half of diabetic patients (3).

Diabetic Peripheral Neuropathy (DPN) is a debilitating complication, with a prevalence rate of 10 $26 \%$ in newly diagnosed diabetes mellitus (4). It causes considerable morbidity, impairs the quality of life and increases mortality. The most common underlying pathophysiology is a consequence of hyperglycemia and micro-angiopathy. DPN leads to further infection increases the risk of foot ulcers and the important cause behind non-traumatic amputations (5).

Magnesium is one of the most abundant intracellular cations with an essential role in biological reactions (6). Studies have found a significant association between hypomagnesemia and the development of Type2 DM. Impairment of magnesium homeostasis may relate to the onset and progression of diabetic complications. Magnesium supplementation has also been shown to delay the development and may reduce the complications related to DM (7).

Despite growing evidence that hypomagnesemia is associated with the outcome of diabetic morbidity, little emphasis is given to estimate magnesium levels in these patients.

Hence, this study is an attempt to estimate serum magnesium with the severity of neuropathy in Diabetic Peripheral Neuropathy. 


\section{MATERIALS AND METHODS}

This study was done in the Department of Biochemistry of Kalinga Institute of Medical Sciences for one year from November 2018-2019. A total of 286 participants with signs and symptoms of DPN i.e., diminished sensation, numbness, burning and aching pain in the toes, feet or legs, decreased or absent ankle reflexes were enrolled in the study. Patients with a history of malabsorption, diarrhea, alcohol consumption, sepsis, pregnancy, lactation, mineral supplementation in recent past and on drugs that may affect serum magnesium levels, eg., diuretics, aminoglycosides, amphotericin B were excluded from our study. Informed consent was taken from all the participants after the proper explanation of the study. Institutional ethical clearance was taken before the commencement of the study.

The venous blood sample was collected after 8 hours of fasting for estimation of Fasting Blood Sugar (FBS), serum sodium, potassium, calcium, serum uric acid, glycated hemoglobin $\left(\mathrm{HbA}_{1} \mathrm{C}\right)$ and serum magnesium. Post-Prandial Blood Sugar (PPBS) was done after two hours of food intake. FBS, PPBS was done by hexokinase method and serum magnesium (Reference range 1.7 - $2.6 \mathrm{mg} / \mathrm{dl}$ ) was done by Chlorophosphonazo method using Cobas Integra 400. $\mathrm{HbA}_{1} \mathrm{C}$ was done by the HPLC method using BIORAD D10 (Reference range 4-6\%). Vibration Perception Threshold (VPT) scores were determined using a Vibrosense Digital Biothesiometer to assess the severity of neuropathy and were classified into Normal (VPT <15V), mild (VPT $=15-20 \mathrm{~V}$ ), moderate $(\mathrm{VPT}=20-25 \mathrm{~V})$ and severe $(\mathrm{VPT}>25 \mathrm{~V})$. Serum magnesium was correlated with FBS, PPBS, $\mathrm{HbA}_{1} \mathrm{C}$ and different severities of neuropathy.

\section{Statistical analysis}

Data were expressed as mean \pm SD for normal distribution variables. Categorical variables were presented as a percentage. Differences between the groups were analyzed by one-way ANOVA. Bonferroni correction was used for post-hoc analysis. Correlation between serum magnesium and other parameters in DPN was done by Pearson's correlation coefficient. $\mathrm{P}<0.05$ was considered statistically significant. All the statistical analyses were done in STATA.

\section{RESULTS}

Table 1 depicts the demographic and biochemical parameters in DPN study participants. The mean age of our study population was $45.74 \pm 9.47$ years. FBS and PPBS was $124.76 \pm 31.54 \mathrm{mg} / \mathrm{dL}$ and $170.91 \pm$ $41.90 \mathrm{mg} / \mathrm{dL}$ respectively. Serum sodium, potassium, calcium, and uric acid were within the normal range. $\mathrm{HbA}_{1} \mathrm{C}$ was $7.37 \pm 1.04 \%$. Mean serum magnesium in our study group was $1.62 \pm 0.38 \mathrm{mg} / \mathrm{dL}$.
Table 1: Demographic and biochemical parameters in DPN

\begin{tabular}{|c|c|}
\hline Parameters & $\begin{array}{c}\text { Mean } \pm \text { SD } \\
(\mathbf{n = 2 8 6})\end{array}$ \\
\hline Age (in yrs.) & $45.74 \pm 9.47$ \\
\hline FBS (mg/dL) & $124.76 \pm 31.54$ \\
\hline PPBS (mg/dL) & $170.91 \pm 41.90$ \\
\hline Serum Sodium (meq/L) & $137.18 \pm 11.82$ \\
\hline Serum Potassium (meq/L) & $4.28 \pm 0.71$ \\
\hline Serum Calcium (meq/L) & $9.67 \pm 0.50$ \\
\hline Serum Uric Acid (mg/dL) & $4.81 \pm 1.42$ \\
\hline Glycated Haemoglobin (\%) & $7.37 \pm 1.04$ \\
\hline Serum Magnesium (mg/dL) & $1.62 \pm 0.38$ \\
\hline VPT (volts) & $22.91 \pm 7.76$ \\
\hline
\end{tabular}

Table 2: Distribution of severity of neuropathy according to VPT scoring

\begin{tabular}{|c|c|c|}
\hline Categories & Frequency & \% \\
\hline Normal (VPT $<15 \mathrm{~V})$ & 38 & 13.29 \\
\hline Mild (VPT $=15-20 \mathrm{~V})$ & 101 & 35.31 \\
\hline Moderate $(\mathrm{VPT}=20-25 \mathrm{~V})$ & 52 & 18.18 \\
\hline Severe $(\mathrm{VPT}>25 \mathrm{~V})$ & 95 & 33.22 \\
\hline
\end{tabular}

Table 3: Serum magnesium levels with severity of neuropathy

\begin{tabular}{|c|c|c|c|c|c|}
\hline $\begin{array}{c}\text { Severity } \\
\text { of } \\
\text { Neurop } \\
\text { athy }\end{array}$ & $\begin{array}{c}\text { Nor } \\
\text { mal } \\
(<15 \\
\text { v) }\end{array}$ & $\begin{array}{l}\text { Mild } \\
(15- \\
20 v)\end{array}$ & $\begin{array}{c}\text { Moder } \\
\text { ate } \\
(20- \\
25 v)\end{array}$ & $\begin{array}{l}\text { Severe } \\
(>25 v)\end{array}$ & $\begin{array}{c}\mathbf{P} \\
\text { value }\end{array}$ \\
\hline $\begin{array}{c}\text { Serum } \\
\text { Magnesi } \\
\text { um } \\
(\mathrm{mg} / \mathrm{dL})\end{array}$ & $\begin{array}{c}1.75 \\
\pm 0.3 \\
7\end{array}$ & $\begin{array}{c}1.71 \pm \\
0.34\end{array}$ & $\begin{array}{c}1.71 \pm 0 . \\
35\end{array}$ & $\begin{array}{c}1.42 \pm 0 . \\
37\end{array}$ & $<0.05$ \\
\hline
\end{tabular}

Table 4: Correlation of serum magnesium with FBS, PPBS, $\mathrm{HbA}_{1} \mathrm{C}$ and VPT score in DPN

\begin{tabular}{|c|c|c|}
\hline & \multicolumn{2}{|c|}{ Serum Magnesium } \\
\hline Parameters & r value & P Value \\
\hline FBS & -0.12 & $<0.05$ \\
\hline $\mathrm{PPBS}$ & -0.17 & $<0.05$ \\
\hline $\mathrm{HbA}_{1} \mathrm{C}$ & -0.26 & $<0.001$ \\
\hline $\mathrm{VPT}$ & -0.43 & $<0.001$ \\
\hline
\end{tabular}

Table 5: Correlation between $\mathrm{HbA}_{1} \mathrm{C}$ and serum magnesium with severity of neuropathy

\begin{tabular}{|c|c|c|}
\hline Categories & r value & p value \\
\hline Mild & -0.17 & 0.07 \\
\hline Moderate & -0.23 & $<0.05$ \\
\hline Severe & -0.28 & $<0.05$ \\
\hline
\end{tabular}

Table 2 shows that $35.31 \%$ of our study group presented with mild neuropathy with VPT scoring 1520V and $33.22 \%$ presented with severe neuropathy with VPT scoring $>25 \mathrm{~V}$. Table 3 shows there was a significant decrease $(\mathrm{p}<0.05)$ in serum magnesium with an increase in severity of DPN which was statistically significant. A significant correlation was seen between serum magnesium and FBS, PPBS, $\mathrm{HbA}_{1} \mathrm{C}$ and VPT scoring in DPN patients (Table 
4). Table 5 shows that there was a significant correlation between $\mathrm{HbA}_{1} \mathrm{C}$ and serum magnesium $(\mathrm{p}<0.05)$ in moderate and severe DPN whereas, no such significant correlation was seen in mild DPN.

\section{DISCUSSION}

Diabetes mellitus is the most common disorder among endocrine disorders that are associated with hypomagnesemia. The development of complications of T2DM including DPN is related to the level of glycemic control. Hypomagnesemia has shown to cause insulin-resistant state, and poor glycemic control and hence associated with Type 2 DM and its complications (8). In this study, DPN patients were classified into mild, moderate and severe by their VPT scoring. Serum magnesium which has a close relationship with Type $2 \mathrm{DM}$ and is associated with various complications of Type $2 \mathrm{DM}$ has been estimated and its relationship with the severity of DPN has been found.

The mean age of DPN patients in our study was $(45.74 \pm 9.47)$ yrs. Similarly, in the study done by Yossef et al., mean age was $48.70 \pm 6.25$ years (9). But in the study done by Arpaci et al., mean age was 55 years (7). Hence in our participants' complications developed much earlier compared to other studies. $\mathrm{HbA}_{1} \mathrm{C}$ in DPN patients in our study was $7.37 \pm 1.04$ $\%$. Renuka et al., in their study had $\mathrm{HbA}_{1} \mathrm{C}$ in a range of $7.5 \pm 1.7 \%$ (10). High levels of glycated hemoglobin suggest poor glycemic control and is an important risk factor for DPN.

In our study $58.39 \%$ of participants had serum magnesium less than $1.7 \mathrm{mg} / \mathrm{dL}$. Similarly, a study done by Seyoum et al., hypomagnesemia was present in $65 \%$ of diabetes Mellitus (11). A study done by Hyasat et al., found $19 \%$ of patients out of 1105 were hypomagnesemic (95\% CI, 16.8\%-21.4\%) which was higher than that observed among non-diabetics in population-based National Vitamin D study $(0.7 \%)$ (95\% CI, $0.48 \%-1.078 \%$ ) (12). Magnesium plays an important role in the phosphorylation reaction of glucose and its metabolism. Its deficiency has been implicated in insulin resistance, carbohydrate intolerance, dyslipidemia and complications of Diabetes Mellitus. Intracellular magnesium plays a role in regulating insulin action and insulin-dependent glucose uptake. Magnesium deficiency reduces tyrosine kinase activity, post-receptor activity and eventually contributes to the development of insulin resistance. Also, in patients with magnesium deficiency, intracellular calcium is increased. Increased calcium, in turn, interrupt response of skeletal muscles and adipocytes to insulin leading to insulin resistance. In turn, insulin deficiency and resistance can affect tubular reabsorption of magnesium (13).

There was a significant correlation between serum magnesium and FBS, PPBS, $\mathrm{HbA}_{1} \mathrm{C}$ in diabetic neuropathy patients. A significant relationship was seen between serum magnesium and $\mathrm{HbA}_{1} \mathrm{C}$ in moderate and severe neuropathy whereas not in mild neuropathy. Arpaci et al., found a weak negative correlation between serum magnesium and $\mathrm{HbA}_{1} \mathrm{C}$ levels $(r=-0.110, p=0.004)(7)$. Kumar et al., in their study found a statistically significant increase in FBS, PPBS, and $\mathrm{HbA}_{1} \mathrm{C}$ in hypomagnesemic Type $2 \mathrm{DM}$ patients (14). Rao et al., found higher FBS, PPBS, and $\mathrm{HbA}_{1} \mathrm{C}$ among Type $2 \mathrm{DM}$ with serum magnesium $<1.7 \mathrm{mg} / \mathrm{dL}(15)$.

Serum magnesium decreased significantly with the severity of neuropathy. Ramachandra et al., found significantly lower serum magnesium in diabetic patients with microvascular complications (16). Chu et al., Zhang et al., and Renuka et al., in their study showed that lower serum magnesium was significantly associated with derangement in peripheral nerve function and pathophysiologic features of DPN $(3,11,17)$. Barry et al., in their study found that $80 \%$ of diabetic patients had hypomagnesemia but there was no association between hypomagnesemia and micro-angiopathic complications (18).

Though multiple pathogeneses of DPN have been suggested, oxidative stress, inflammation, and decreased intracellular inositol concentrations contribute to the progression of the disease. Magnesium not only decreases tissue susceptibility to oxidative damage but also has the indirect antioxidant capacity $(17,18)$. Studies have also demonstrated that low serum magnesium concentration is closely associated with increased inflammation $(19,20)$. Besides magnesium has been reported to increase intracellular inositol concentrations by enhancing the affinity of the transport system for inositol, inhibiting further damage to the nervous system, suggesting low serum magnesium might affect peripheral nerve function through axonal degeneration (3).

\section{CONCLUSION}

Hypomagnesemia was found to be associated with DPN one of the microvascular complications of Type 2DM. So, it is important to regularly monitor magnesium levels in all Type 2 DM. But there are certain limitations to our study. Most of the participants in our study were being treated with antidiabetic or anti-hypertensive drugs which might affect the results. We only measured total serum magnesium which does not take into account the alterations in ionized magnesium concentrations. Further, it was a cross-sectional study with a small sample size so for the cause and effect relationship large scale clinical trials are needed to determine whether magnesium supplementation could be effective in reducing the incidence of DPN in Type 2 DM.

\section{ACKNOWLEDGEMENT}

We thank all the participants of the study for their cooperation and technical staffs of the Biochemistry 
laboratory for their valuable help for the commencement of the study.

\section{CONFLICTS OF INTEREST}

Authors have no conflict of interest to disclose.

\section{REFERENCES}

1. Cho, N. H., Shaw, J., Karuranga, S., Kuang, Y., Fernandes, J.D.R., Ohlrogge, A. W. IDF diabetes atlas: Global estimates of diabetes prevalence for 2017 and projections for 2045 . 2018; 138: 271-281.

2. Skar, M., Villumsen, A. B., Christensen, D. L., Petersen, J. H., Deepa, M., Anjana, R. M., et al., Increased risk of type 2 diabetes with ascending social class in urban South Indians is explained by obesity: The Chennai urban rural epidemiology study (CURES-116). Indian Journal of Endocrinology and Metabolism. 2013; 17(6): 1084-1089.

3. Chu, C., Zhao, W., Zhang, Y., Li, L, Lu, J., Jiang, L., et al., Low serum magnesium levels are associated with impaired peripheral nerve function in type 2 diabetic patients. Scientific Reports. 2016; 6: 32623.

4. Khawaja, N., Abu-Shennar, J., Saleh, M., Dahbour, S. S., Khader Y. S., Ajlouni, K. M. The prevalence and risk factors of peripheral neuropathy among patients with type 2 diabetes mellitus; the case of Jordan. Diabetology and Metabolic Syndrome. 2018; 10: 8. https://doi.org/10.1186/s13098-0180309-6.

5. Amin, N., Doupis, J. Diabetic foot disease: From the evaluation of the "foot at risk" to the novel diabetic ulcer treatment modalities. World Journal of Diabetes. 2016; 7(7): 153-164.

6. Al Alawi, A. M., Majoni, S. W., Falhammar, H. Magnesium and Human Health: Perspectives and Research Directions. International Journal of Endocrinology. 2018: 9041694. https://doi.org/10.1155/2018/9041694

7. Arpaci, D., Tocoglu, A. G., Ergenc, H., Korkmaz, S., Ucar, A., Tamer, A. Associations of serum Magnesium levels with diabetes mellitus and diabetic complications. Hippokratia. 2015; 19(2): 153-157.

8. Dasgupta, A., Sarma, D., Saikia, U. K. Hypomagnesemia in Type 2 DM. Indian journal of endocrinology and metabolism. 2012; 16(6): 1000-1003.

9. Yossef, H., Ghanem, N., Jarlin, U. A., Shaker, O. G. Relation of serum magnesium level to microvascular complications and components of metabolic syndrome inpatients with Type 2 DM. The Egyptian journal of Internal Medicine. 2017; 29: 100-104.

10. Renuka, N. P., Naveen, C. R. Nitric Oxide in Diabetic Patients and its relationship with $\mathrm{HbA}_{1} \mathrm{C}$. International Journal of Pharmaceutical and Clinical Research. 2014; 6(2): 146-148.

11. Seyoum, B., Siraj, E. S., Saenz, C., Adul, K. J. Hypomagnesemia in Ethiopian with Diabetes Mellitus. Ethiopian Disease. 2008; 18(2): 147-151.

12. Hyassat, D., Al Sitri, E., Batieha, A., El-Khateeb, M., \& Ajlouni, K. (2014). Prevalence of Hypomagnesaemia among Obese Type 2 Diabetic Patients Attending the National Center for Diabetes, Endocrinology and Genetics (NCDEG). International Journal of Endocrinology and Metabolism, 12(3),

e17796. https://doi.org/10.5812/ijem.17796.

13. Kostov, K. Effects of magnesium deficiency on mechanisms of insulin resistance in type 2 Diabetes: Focussing on the process of insulin secretion and signalling. International Journal of Molecular Sciences. 2019; 20(6): 1351-1360.

14. Kumar, P., Bhargava, S., Agrawal, P. K., Garg, A., Khosia, A. Association of serum magnesium with type 2 diabetes mellitus and Diabetic retinopathy. Journal of Family Medicine and Primary care. 2019; 8(5): 1671-1677.
15. Rao, P., Shariff, M. G. Serum magnesium levels in Type 2 Diabetic patients with microalbuminuria. International Journal of scientific study. 2015; 3(4): 12-15.

16. Ramachandran, A., Ma, R. C., Snehalatha. C. Diabetes in Asia. Lancet. 2010; 375: 408-418.

17. Zhang, Q., Ji, L., Zheng, H., Li, Q., Xiong, Q., Sun, W., et al., low serum phosphate and magnesium levels are associated with peripheral neuropathy in patients with type 2 Diabetes Mellitus. Diabetes Research and Clinical Practice. 2018; 146: 1-7.

18. Barry, N.O.K., Ndour, M. A., Djite, M., Diedhio, D., Kandji ,P. M., Ndour, E. H., et al., Association of magnesium status with poor glycemic control and microangiopathic complications (neuropathy and nephropathy) in Diabetes patients in Dakar. Advances in Biochemistry. 2019; 7(3): 5964.

19. Weglicki, W. B. Hypomagnesemia and inflammation: clinical and basic aspects. Annual Reviews of Nutrition. 2012; 32: 55-71.

20. Nielsen, F. H. Magnesium deficiency and increased inflammation: current perspectives. Journal of Inflammation Research. 2018; 11: 25-34. 